\title{
Beco como lugar de intervenção para acesso às sensibilidades urbanas e suas memórias ${ }^{1}$
}

\author{
Alley as a place of intervention to access urban sensibilities \\ and their memories
}

\section{Resumo:}

Neste artigo pensa-se 0 beco como lugar de representação simbólica da cidade e, também, como espaço para intervenções urbanas, a partir de um conjunto de significações que fazem da sua invisibilidade material, fonte para proposição de novas leituras, narrativas e sensibilidades. Em uma perspectiva que articula os campos do turismo cultural e da história das sensibilidades, o texto propõe refletir as experiências do indivíduo no espaço, como meio de perceber o sentido do beco, tal como ele é dado pela construção dos imaginários urbanos ao longo do tempo, assim como por uma nova categoria de interpretação que aqui se sugere, a realização de um itinerário histórico-cultural. Os antigos

\footnotetext{
${ }^{1} \mathrm{O}$ texto deste artigo é uma adaptação conjunta de algumas ideias que surgiram durante a pesquisa e a escrita da dissertação de mestrado em Memória Social e Bens Culturais do Unilasalle/Canoas, intitulada "Itinerário histórico-cultural dos becos de Porto Alegre no final do século XIX", de Luciana Rodrigues Gransotto, defendida em 23 de junho de 2016, orientada pela Dra. Nádia Maria Weber Santos e co-orientada pela Dra. Zilá Bernd.

${ }^{2}$ Pós-Doutora pela Université Laval (Québec/Canadá). Doutora em História pela UFRGS. Bolsista de Produtividade em Pesquisa do CNPq. Professora convidada do Mestrado Profissional em Memória e Acervos da Fundação Casa de Rui Barbosa do Rio de Janeiro. Curadora do Acervo Sandra Jatahy Pesavento no Instituto Histórico e Geográfico do Rio Grande do Sul. E-mail nnmmws@gmail.com

${ }^{3}$ Doutoranda no Programa Interdisciplinar em Ciências Humanas, na UFSC. Bacharel em Turismo pela PUCRS, Mestre em Memória social e Bens Culturais pelo Unilasalle/Canoas. E-mail: lucianargransotto@gmail.com
} 
becos do final do século XIX de Porto Alegre são trazidos para esse contexto como referência de espaço que não resistiu às transformações da modernidade, mas que ainda abarcam, significativamente, traços e conteúdos históricos que estão envolvidos nas discussões contemporâneas sobre territórios urbanos excluídos, presentes nas memórias da cidade.

Palavras-chave: Beco, Sensibilidades, Imaginário Urbano.

\begin{abstract}
:
In this article, the alley is conceived as a place of symbolic representation of the city as well as a space for urban interventions. This conception stems from a selection of meanings that turns its material invisibility into a fertile source for new interpretations and narratives. Through a perspective that combines cultural tourismand the history of sensibilities, this text proposes to reflect the experiences of the individual within space as a manner to perceive the meaning of an alley, both through the creation of social imaginationthroughout time, as well as through a new category of interpretation that involves a historical and cultural journey. The old 19th century alleys of Porto Alegre, Rio Grande do Sul, Brazil are examined in this fashion. These alleys were not able to withstand modernization, yet however they maintain historical features and elementsthat are included in contemporary discussions surrounding excluded urban areas and the memory of the city. XXX
\end{abstract}

Keywords: Alley, Sensibilities, Urban Imaginary.

\title{
Introdução
}

"A História busca sempre a inteligibilidade de algo que se coloca diante da experiência do vivido e o seu grande desafio é conseguir chegar nos códigos de sentido e nas regras de sociabilidade de um outro tempo"

(Sandra Jatahy Pesavento)

O beco (que, em termos de especificidades espaciais, é curto, estreito e, às vezes, sem saída; quando se trata da acepção social da palavra, pode carregar significados negativos, como um lugar sinistro, sujo e, ocasionalmente, perigoso) pode ser pensando como lugar de representação simbólica da cidade, mas também como 
espaço para intervenções urbanas, a partir de um conjunto de significações que fazem da sua invisibilidade material, fonte para proposição de novas leituras, narrativas e sensibilidades.

Os antigos becos do final do século XIX da cidade de Porto Alegre são trabalhados neste artigo como referências de espaço que não resistiram às transformações da modernidade e que ainda abarcam, significativamente, traços e conteúdos históricos que estão envolvidos nas discussões contemporâneas sobre territórios urbanos excluídos, presentes nas memórias da cidade.

Em uma perspectiva que articula os campos do turismo cultural e da história das sensibilidades, o texto propõe refletir as experiências do indivíduo (do passado e do presente) no espaço, como meio de perceber o sentido do beco, tal como ele é dado pela construção dos imaginários urbanos ao longo do tempo, assim como por uma nova categoria de interpretação que aqui se sugere, a realização de um itinerário histórico-cultural. Intenta-se atualizar a discussão sobre espaço urbano, memória sensível dos lugares e seu uso socialmente compartilhado pelos viajantes e citadinos, fazendo dialogar entre si as duas áreas de nosso interesse supracitadas: turismo cultural e história das sensibilidades.

Parte-se, primeiramente, de uma noção geral sobre becos, trazida pela Pesavento (2014):

\footnotetext{
Como via ou espaço aberto da cidade, tanto no registro linguístico português quanto no brasileiro, o beco apresenta duas significações distintas, uma espacial, topográfica e uma social, moral. No primeiro significado, remontaria às origens latinas da palavra, o beco aponta para um tipo especial de rua, seja pelo seu traçado, seja pelas suas características enquanto elemento estruturado da urbs: curto, estreito, às vezes sem saída (PESAVENTO, 2014, p. 126-127).
}

Esta autora aponta que os becos, praticamente nascidos com a cidade - sejam aqueles de Alfama, em Lisboa, ou na cidade colonial do Rio de Janeiro -, não surgem de um traçado oficial, ou seja, eles não se originaram através de ações de iniciativa pública e sim fizeram-se de maneira espontânea, ocupando espaços entre as vias principais, geralmente transversais a elas. Portanto, nesse sentido, o beco "é uma abertura secundária ou interseção entre ruas principais" e, "face a essa significação 
espacial urbana, o beco assume o equivalente a viela, travessa ou atalho" (PESAVENTO, 2014, p. 127).

Na antiga cidade de Porto Alegre, capital do Rio Grande do Sul (Brasil), a ideia de beco sustentava-se a partir das plantas dos séculos XVIII e XIX, as quais mencionavam os becos como semelhantes às ruas, em termos de largura e de extensão, porém, com habitações mais modestas. Já no século XX, com a atualização e modernização das cidades, considerando os planos de renovação urbana, alguns becos foram alargados, transformando-se em ruas (PESAVENTO, 2004). Nesse entremeio, principalmente no período que compreende o final do século XIX e início do século $\mathrm{XX}$, devido ao crescimento da cidade e, junto a ele, alterações no traçado urbano e estabelecimento de novas relações sociais e políticas, os becos transformam-se em um outro lugar, espaço de embates e conflitos entre cidadãos e não-cidadãos, delimitação segundo as representações sociais da época.

Apesar da destruição quase que completa dos becos, em termos físicos (salvo algumas ruas que ainda mantém rastros e resquícios da materialidade dos seus antigos becos), eles permanecem na forma de escritos, como as narrativas dos textos literários, as crônicas de jornais ou a partir de rastros imagéticos -, sejam eles registros fotográficos ou a cartografia -, recuperados e conservados até hoje.

O exercício deste artigo será trazer para o presente, através da recuperação do imaginário urbano e das reminiscências dos antigos becos de Porto Alegre, as dinâmicas sociais praticadas nesse território, assim como o deslocamento de significados do lugar, propondo a realização de um itinerário histórico-cultural, praticado por cidadãos e viajantes.

Utiliza-se como ponto de partida a descrição dos becos inserida na obra da historiadora Sandra Pesavento, especialmente em Uma outra cidade - o mundo dos excluídos no final do século XIX (São Paulo: editora Companhia Nacional, 2001) e coteja-se com outros referenciais sobre os mesmos becos da urbe. As reflexões sobre sensibilidade, memória e questões correlatas (memórias afetivas dos espaços, entre outras) estão embasadas teoricamente, no texto clássico de Lucien Febvre, La sensibilité et l'Histoire - commentre constituer la vieaffective d'autrefois? (Brionne: Gérard Monfort, 1984) e nas concepções contemporâneas de Aleida Assmann, em seu livro Espaços da Recordação - formas e transformações da Memória Cultural 
(Campinas: editora da UNICAMP, 2011), e, também, em vários textos de Sandra Pesavento, pioneira no campo da História das Sensibilidades no Brasil. As referências sobre Turismo Cultural levam em conta as reflexões inseridas principalmente na obra de Frank Michel, Désirs d'Ailleurs - essai d'Antropologie des Voyages (Quebec: Les Presses de l'Université Laval, 2004).

\section{Beco, lugar do 'outro'}

Porto Alegre, na metade do século XVIII, recebia os colonos açorianos que se assentaram às margens do Guaíba, terras de sesmaria de Jerônimo de Ornelas, apresentando, já na metade do século seguinte, a existência de becos, os quais foram se estabelecendo de forma não ordenada.Até então o beco não carregava conotações depreciativas e nem se distinguia tão significativamente das demais vias da cidade. $O$ beco não era "[...] definidamente o espaço do pobre, nem a viela ou a rua sem saída, nem obrigatoriamente estreito, nem exclusivamente composto de moradias modestas" (PESAVENTO, 2001b, p.111).

Os relatos dos viajantes do século XIX - como os de Auguste Saint-Hilaire, Arsène Isabelle, Avé-Lallemant, Oscar Canstatt, Wilhelm Breitenbach, Moritz Schanz -, de forma proposital ou não, a partir de Mello (2010), não registram nenhum aspecto negativo - tal como sujos e promíscuos - com relação aos becos e vielas. O beco, como espaço público, não era visto como um problema ou como um lugar perigoso.

O aumento considerável da população na área central da cidade, impulsionado pelas construções e loteamentos, em resposta, principalmente, à chegada de imigrantes e aumento da população, fez com que houvesse a necessidade de expansão e investimento no perímetro urbano. Para a população burguesa, conforme Leenhardt (2015), a chegada destes imigrantes - vindos das áreas rurais - acaba virando um "sintoma das consequências dramáticas", principalmente porque, "[...] não se trata somente dos camponeses pobres, mas também dos escravos negros recém libertos, os quais instalam as suas festas, e em particular o batuque, nos becos do centro" (LEENHARDT, 2015, p. 25-26). 
É precisamente neste momento que as diversas representações dos espaços intersticiais chamados "becos" se difundem e divergem. De repente, desvinculando-se da noção descritiva dos urbanistas, aparece uma nova definição do "beco", entre fantasmagoria e ideologia! No imaginário das novas classes médias, recém instaladas no centro da cidade, o "beco" vira um lugar mal-afamado, um lugar de libertinagem e de perigos (LEENHARDT, 2015, p. 25).

Esse cenário, registrado nas crônicas de jornais por fazer parte do imaginário da cidade do final do século XIX, tornou-se um lugar de contravenção, de cenas que remetem a uma outra cidade, onde a moradia e os estabelecimentos comerciais eram considerados infectos e um foco de sujeira, tanto em termos de higiene quanto de indivíduos que os frequentavam.

A adjetivação e acepção utilizada na época possibilitam uma melhor compreensão do que foi esse "outro lugar" ou essa "outra cidade". Um território que abrigava estabelecimentos como "bodegas", "tavernas", "tascas", "conventilhos", "espeluncas", "tavolagens", "bordeis", "alcouces", "lupanares", "bengues", "zum-gús", "maternidades", "casebres", "cortiços", e "pardieiros", situava-se como um lugar marcado pelo grande número de crimes e desordens.

Dentro desse território também faziam parte os seus personagens, principais frequentadores e habitantes dos becos da cidade, entre eles prostitutas, marinheiros, soldados, praças, policiais e aqueles indivíduos considerados 'desocupados'. Nesse mundo de indivíduos que transgrediam as leis, há a representação estigmatizada da mulher, sempre referenciada de forma pejorativa e irônica, evidenciando a sociedade preconceituosa e machista da época. Nomes como "messalinas espertas", "madalenas impertinentes", "ratoneiras", "rameiras", "dulcinéias", "chinas", "tagarras", "potreiras", "caftinas" e "alcoviteiras", representavam as mulheres praticantes de atividades consideradas ilícitas, segundo os padrões estabelecidos, assim como pelas representações sociais da época.

Dentro da cidade há uma má cidade que se encerra. A urbs moderna constrói as suas muralhas internas, simbólicas, mas nem por isso menos sólidas que as antigas, de pedra. Elas são estruturadoras de comportamentos, imagens e

\footnotetext{
${ }^{4}$ As palavras e expressões a seguir foram recuperadas principalmente das obras de Sandra Pesavento, com base nos periódicos da época.

5 Da mesma forma como a referência anterior, os termos utilizados foram recuperados a partir, principalmente, das obras de Sandra Pesavento, com base nos periódicos da época.
} 
discursos discriminatórios. O 'outro', o perigoso, o indesejado, habita intramuros (PESAVENTO, 2001a, p. 26).

Nessa operação, a construção da identidade e do pertencimento se desenvolve, também, a partir do confronto e da diferença. Aspectos estético, higiênico e principalmente moral, podem determinar o processo de inclusão ou exclusão de um território, assim como de seus grupos sociais, de forma que, mais cedo ou mais tarde, as comunidades são deslocadas para que haja uma reconfiguração - e atualização do espaço, alterando a sua dinâmica. Mas antes, são marginalizadas, em um processo de estigmatização, pois, conforme Pesavento (2001a), a exclusão está relacionada à representação das práticas sociais discriminatórias, construídas ao longo da história, e que se apresentam na forma de discursos e palavras.

Dentro desse contexto, segundo Barros (2006), "os sistemas discriminatórios giram em torno da construção atualizada de uma distinção entre duas ou mais categorias", que no caso de Porto Alegre, no final do século XIX, refere-se aos moradores (homens e mulheres) dos becos, considerados não-cidadãos, e o restante da população, indivíduos incluídos e integrados à sociedade. As desigualdades sociais, iniciadas pela discriminação, acabam por estabelecer tratamentos desiguais de uma categoria em relação à outra, através da limitação ou negação da participação política até a sua máxima, ou seja, a "segregação espacial ou à exclusão social" (BARROS, 2006, p. 207-208).

No território dos antigos becos de Porto Alegre -, 'desordeiros' e 'turbulentos' ocupavam o lugar de enclave, do estrangeiro, ou seja, ocupavam o 'lugar do outro'. Cruzando as avenidas principais, eram locais onde não se recomendava atravessar. Os principais jornais da época, A Gazetinha e Gazeta da Tarde, mais ricos em artigos de natureza moral, destacavam as práticas que envolviam vícios e prostituição. Já os Jornais O Mercantil, Jornal do Comércio e Correio do Povo voltavam-se para o registro de informações acerca de crimes e contravenções. ${ }^{6}$ As narrativas desses periódicos através de crônicas e notícias - a respeito da vida nos becos, contribuíram

\footnotetext{
${ }^{6} \mathrm{Na}$ obra Uma outra cidade - o mundo dos excluídos no final do século XIX (São Paulo: editora Companhia Nacional, 2001), Sandra Pesavento recupera as crônicas e notícias dos principais jornais da época, a respeito dos becos e das suas histórias.
} 
significativamente para a construção das imagens e da formação do imaginário urbano da época.

Os principais becos da cidade de Porto Alegre, entre o final do século XIX e início do século $X X$, ocupavam consideravelmente o espaço urbano e estavam concentrados, em sua maior parte, no que se denominava o Primeiro Distrito. ${ }^{7}$

Dentre todos os antigos becos que fizeram parte da história da cidade de Porto Alegre, elencamos três deles para compor o itinerário histórico-cultural que propomos. Eles nos parecem importantes dadas as suas especificidades, considerando, principalmente, a sua validade em termos de formação de imaginários assim como de construção das relações sociais estabelecidas nesses espaços, justificando, portanto, reinvestir na atualização das suas memórias.

O primeiro, o beco da Ópera, sem conotações depreciativas - tal como os becos do Poço e do Fanha - tem relevância para a cidade pois ali foi construída a primeira casa de teatro, tornando-se um importante referencial para Porto Alegre, cidade que valoriza e invoca continuamente a cena cultural e artística. O segundo beco é o emblemático beco do Poço, o mais abordado nas crônicas de jornais e nos boletins policiais da época. Pode-se dizer que o beco do Poço é o registro - a partir das crônicas, mas também do imaginário urbano - do que era um lugar feio, mal frequentado e insalubre no final do século XIX. O terceiro, o beco do Fanha, recupera a antiga prática popular de nomear as ruas a partir dos seus referenciais, nesse caso de um taberneiro, que acaba ficando conhecido por ter construído as primeiras edificações na rua. Nesse beco também há a interferência policial e dos jornais, pois era rotineira a presença de moradores "baderneiros" e estabelecimentos que incitavam práticas ilegais, como jogos e prostituição.

$\mathrm{Na}$ articulação destes "lugares do outro" com nossas reflexões sobre memória, sensibilidades e imaginário urbano, daremos um sentido atualizado aos antigos becos do final do século XIX de Porto Alegre, que são recuperados, como já foi dito, como referência de espaços nos quais os traços e os conteúdos históricos sobre territórios urbanos excluídos permanecem no imaginário da população.

\footnotetext{
${ }^{7}$ Apesar da maior concentração de marginalidade estar presente no 1ํㅡㄹ Distrito, outros núcleos urbanos fizeram parte da representação de exclusão da cidade de Porto Alegre, como a Colônia Africana e o Areal da Baronesa.
} 


\section{Memória, sensibilidades e imaginário urbanos: ressignificando Becos no mundo contemporâneo}

Neste tópico serão aproximadas as noções de memória, sensibilidades e imaginário urbano aos estudos sobre os becos, a fim de que se possa demonstrar, na sequência do texto, a nova categoria de interpretação dos becos que o artigo sugere.

Para Lucien Febvre (1987), em seu original texto "La Sensiblité et I'Histoire comment reconstituer la vie affective d'autrefois?" (A sensibilidade e a História - como reconstituir a vida afetiva de antigamente? - Tradução nossa), sensibilidade evoca a vida afetiva e suas manifestações, ou seja, as emoções, que, embora possam ser individuais e "inexoravelmente subjetivas" (FEBVRE, 1987, p. 97 - tradução nossa), se expressam de forma coletiva, ou melhor dito, "elas implicam relações de homem e homem, relações coletivas" (FEBVRE, 1987, p.98 - tradução nossa). Ou seja, "as emoções são contagiosas" (FEBVRE, 1987, p.98 - tradução nossa). Colocado de outra forma - e aqui estamos utilizando o texto deste autor e o reinterpretando a partir de nossa tradução -, as emoções podem até nascer no indivíduo, porém sua expressão é o "resultado de uma tal série de experiências de vida comum, de reações semelhantes e simultâneas ao choque de situações idênticas" (p. 98 - tradução nossa). Em suma, emoção é fruto de uma fusão, de uma "redução recíproca de sensibilidades diversas" (FEBVRE, 1987, p.98 - tradução nossa), que, por uma espécie de 'contágio mimético' passa aos outros indivíduos. (FEBVRE, 1987, p. 97-98 - tradução nossa).

Desta forma, afirmamos que as emoções são elementos constituintes das sensibilidades que podem ser compartilhadas por uma mesma comunidade afetiva, onde a memória se instala no decorrer do tempo e pode ser recuperada no futuro de uma sociedade através de seus traços, vestígios culturais (ASSMANN, 2011) que, nesta presente reflexão, constituem-se em elementos do imaginário urbano coletivo sobre os Becos da cidade de Porto Alegre do século XIX.

Conforme estudou Pesavento (2005a, 2007a, 2012), essas últimas remetem à esfera do imaginário, da cultura e seu conjunto de significações construído sobre o 
mundo em que vivemos. Tais significados são expressos em representações sensíveis que, mesmo que se refiram a algo que não tenha existência real concreta, o que está colocado para reflexão é a realidade do sentimento, a experiência sensível de viver e enfrentar uma situação/representação portadora de sentido, de significado. É este âmbito do sensível que incide sobre as formas de valorizar, classificar a realidade ou de reagir diante de determinadas práticas sociais, como mostra Pesavento (2007a). Assim, afirma-se que "as sensibilidades são sutis, difíceis de capturar, pois se inscrevem sob o signo da alteridade, traduzindo emoções, sentimentos e valores que não são mais os nossos" (PESAVENTO, 2007a, p.15), mas que deixaram suas marcas nas produções humanas.

\footnotetext{
Recuperar sensibilidades não é sentir da mesma forma, é tentar explicar como poderia ter sido a experiência sensível de um outro tempo pelos rastros que deixou. $O$ passado encerra uma experiência singular de percepção e representação do mundo, mas os registros que ficaram, e que é preciso saber ler, nos permitem ir além da lacuna, do vazio, do silêncio.(PESAVENTO, 2005a, em linha, s/p)
}

A memória, por sua vez, pode ser considerada como o reconhecimento de uma imagem do passado, ocupando-se de rememorações/lembranças reintegradas subjetivamente a esse passado, que não mais volta de forma objetiva, mas que se apresenta nas imagens sensíveis da própria memória. Seguindo este raciocínio, as sensibilidades podem constituir-se em vetores memoriais que deixam suas marcas na objetividade do mundo (SANTOS, 2013). O pesquisador, assim, deve fazer surgir dos escombros remexidos do passado as imagens e, na continuidade da apreensão das rememorações, fazer delas narrativas sensíveis das experiências subjetivas, que se tornarão, no tempo presente, ressignificações importantes daquilo que passou. Aqui, de uma cidade em condições de transformação.

Ainda seguindo Pesavento (2005b), que ao aproximar cidade, espaço e memória escreve sobre a história cultural do urbano, o espaço urbano contém um tempo, encerra uma história e uma memória e supõe uma leitura, que faz da cidade como que um livro de pedra. Para ela, a cidade é uma unidade de espaço e tempo, e nela, com o precioso auxílio da memória - a qual, remontando à Ricoeur (2000), traz o testemunho, a lembrança, para darem credibilidade ao que passou, à rememoração de 
quem lá esteve-pode-se recuperar "vivencias, traçados, materialidade" (PESAVENTO, 2005b, p. 11).

Assim,

\begin{abstract}
Recuperar a cidade do passado implica, de uma certa forma, não apenas registrar lembranças, relatar fatos, celebrar personagens, reconstruir, reabilitar ou restaurar prédios, preservar espaços. Ao salvaguardar a cidade do passado, importa, sobretudo, fixar imagens e discursos de um outro tempo que possam conferir uma identidade urbana. Este é um processo de definição de um pertencimento, composto não apenas pelos registros do mundo material, dados a ver, tangíveis, à disposição do passante, como também aqueles advindos da esfera do imaterial, depositados na memória, nas tradições, na rememoração das vivências passadas, no mundo das coisas ditas. Ou seja, para o resgate da memória e da história de uma cidade é preciso convocar e recolher registros, testemunhos e traços de diferentes naturezas, que possam dar conta das transformações do espaço urbano no tempo. (PESAVENTO, 2005b, p. 11).
\end{abstract}

Os becos do passado da cidade de Porto Alegre inserem-se, pois, aqui como um espaço de memória a ser recuperado, tanto pelo fato desse reconhecimento estar intrinsecamente ligado às questões de identidade da cidade, quanto por razões de valorização do centro histórico de Porto Alegre, seja pelo citadino, seja pelo turista, em uma constante troca simbólica. A alemã Aleida Assmann (2011), na obra Espaços da recordação. Formas e transformações da memória cultural, trabalha uma questão que vem ao encontro da reflexão que aqui se propõe, que é a ideia da memória dos locais. Ela compreende que essa memória seria como aquela que "se recorda dos locais", ou "uma memória que está por si só situada nos locais" ou ainda "porque aponta para a possibilidade de que os locais possam tornar-se sujeitos, portadores da recordação e possivelmente dotados de uma memória que ultrapassa amplamente a memória dos humanos" (ASSMANN, 2011, p. 317).

No plano simbólico, a cidade é um emaranhado de ideias, aspirações e utopias (GRANSOTTO, 2009) e cada cidadão possui em seu "museu imaginário", os seus sonhos, que são, por assim dizer, "armazenados" coletivamente no imaginário urbano, que se materializa, nas expressões da cidade. Ou seja, antes de se materializar, a cidade é imaginada, é idealizada, é sentida em cada indivíduo e em seu conjunto (a urbe). Para Pesavento (2007b), o imaginário urbano, "como todo o imaginário, diz 
respeito a formas de percepção, identificação e atribuição de significados ao mundo, o que implica dizer que trata das representações construídas sobre a realidade - no caso, a cidade" (PESAVENTO, 2007b, p. 15). Assim, a partir das representações da cidade, compreendidas como construções simbólicas (imaginário urbano) e espaços de sociabilidade, as experiências citadinas possibilitam a recuperação da memória daqueles que fizeram parte da história da cidade. (GRANSOTTO, 2016; SANTOS E GRANSOTTO, 2015).

\footnotetext{
Pois, afinal, entre registros de pedra, de papel e reminiscências, o tal passado a recuperar é, na verdade, somente acessível pelo esforço da imaginação, uma vez que se trata de uma experiência que se passou no tempo do já acontecido ou para muito além deste, por fora da experiência do vivido. (PESAVENTO, 2005b, p.11)
}

É nesta senda que, então, percorrem-se alguns becos do passado centenário com os olhos do presente e criam-se estratégias de (re)significação a partir de itinerários histórico-culturais que envolvem imaginários urbanos e emoções (memórias sensíveis) que unem os atores sociais do passado aos citadinos contemporâneos e aos visitantes da urbe.

\section{Itinerário histórico-cultural para (re) interpretação dos becos}

A proposição de nova categoria de interpretação dos becos está relacionada com a experiência turística contemporânea, como possibilidade de aprimoramento do olhar e de transformação. O itinerário histórico-cultural, pensado aqui como exercício que propicia experiências de mobilidade, articula-se com o campo das sensibilidades.

Frank Michel (2004), antropólogo francês, na obra Désirs d'Ailleurs ${ }^{8}$, acredita que os meios, as formas, as ânsias e as motivações de viajar evoluíram, apontando para uma "mudança semiótica depois de uma transformação profunda da sociedade" (MICHEL, 2004, p. 28). A viagem, para ele, é o desejo e o (re) encontro com o outro, é

\footnotetext{
${ }^{8}$ Tradução: Desejo de outros.
} 
uma busca libertária, um mergulho no incomum, no improvável. Michel (2004, p. 10) escreve que "A viagem começa quando nossas certezas acabam. (...) A viagem convida o desejo da alteridade, tanto quanto a de outros lugares (...)".

Em "Relatos de Espaço", capítulo da obra A invenção do Cotidiano, Michel de Certeau (2007, p. 200) aproxima a experiência de viagem a uma "prática do espaço", imbuídas de códigos, comportamentos e controles que organizam as direções, sejam elas lineares ou não. Seus atores - citadinos ou estrangeiros -, relatam a experiência do lugar e orientam, sob a forma de um lugar físico - indicando uma direção -, ou a partir de algum elemento subjetivo - retomando uma recordação -, fazendo com que esses lugares se conectem e transitem entre si. É o que ele intitula como modalidade "epistêmica", aquela relacionada ao conhecimento, "alética", no sentido de existência ou "deôntica", referindo-se aos deveres. Nessa operação narrativa o indivíduo produz enunciados (deslocamentos geográficos, noções de ordem e direção) mas, principalmente, ele exercita o ato de viajar, ele caminha e percorre e cria o seu próprio itinerário.

O turismo cultural como atividade, em uma perspectiva psicossocial, "[...] é uma vivência de participação em novas e profundas experiências culturais estéticas, intelectuais e psicológicas" (PÉREZ, 2009, p.110). A proposição do itinerário históricocultural $^{9}$ dos antigos becos de Porto Alegre, objetivando recuperar aspectos da memória do lugar - o lugar dos becos -, foi pensado de forma a intensificar a percepção do indivíduo no espaço urbano, tal como um processo cognitivo, partindo dos elementos de subjetividade, do imaginário e das práticas e representações sociais do final do século XIX.

Quando se fala em ressignificação de um centro histórico urbano, na reestruturação de seu território, demarcado concreta e simbolicamente, pensamos exatamente nessa possibilidade a partir da transformação do imaginário turístico, através de sua reapropriação do território estrangeiro que é repensado, revitalizado e mesmo transformado na relação com os citadinos - ambos, visitantes e cidadãos, criando e recriando suas identidades com os locais, de formas concretas e simbólicas. Tanto o cidadão como o viajante têm a capacidade de estabelecer uma relação de pertencimento no território que habitam, seja este fixo ou de passagem... Quem é o outro? O citadino ou o turista-viajante? (SANTOS e GRANSOTTO, 2016, p. 267)

\footnotetext{
9 A delimitação e conceituação de itinerários histórico-culturais surgiram a partir de uma pesquisa acadêmica - investigação de mestrado - relacionada às potencialidades do turismo, no que tangem à valorização da memória de um lugar.
} 
O exercício do itinerário é tanto um exercício prático de deslocamento na cidade, considerando a realização de um circuito, como um exercício de imaginação feito pelo caminhante. Postula-se que a caminhada não tem como ser feita nestes espaços sem a internalização realizada a partir dos estímulos de memória e de imaginário, pois os antigos becos - da Ópera, do Poço e do Fanha - não existem mais em sua concretude.

O itinerário sugere um percurso físico a ser realizado nos três antigos becos os quais deram espaço para novas ruas e outros usos. A elaboração de peças gráficas, ou seja,de representações memoriais dos espaços dos becos, foram criadas a partir do imaginário urbano da época, a fim de instigarem outros imaginários e, ao mesmo tempo, contribuírem para que a experiência feita in loco tenha sua percepção apurada.

Denominado de "itinerário dos becos", o itinerário histórico-cultural percorre as três ruas onde estavam localizados os antigos becos da cidade de Porto Alegre no final do século XIX e início do século XX: rua Uruguai (beco da Ópera), avenida Borges de Medeiros (beco do Poço), rua Caldas Junior (beco do Fanha). A primeira peça gráfica (Imagem 1), o mapa do itinerário, meramente ilustrativo aqui, foi criado para indicar onde situavam-se (aproximadamente) os antigos becos, segundo a localização das suas ruas atuais, ou seja, dos (mesmos) espaços ocupados após a destruição dos becos. 


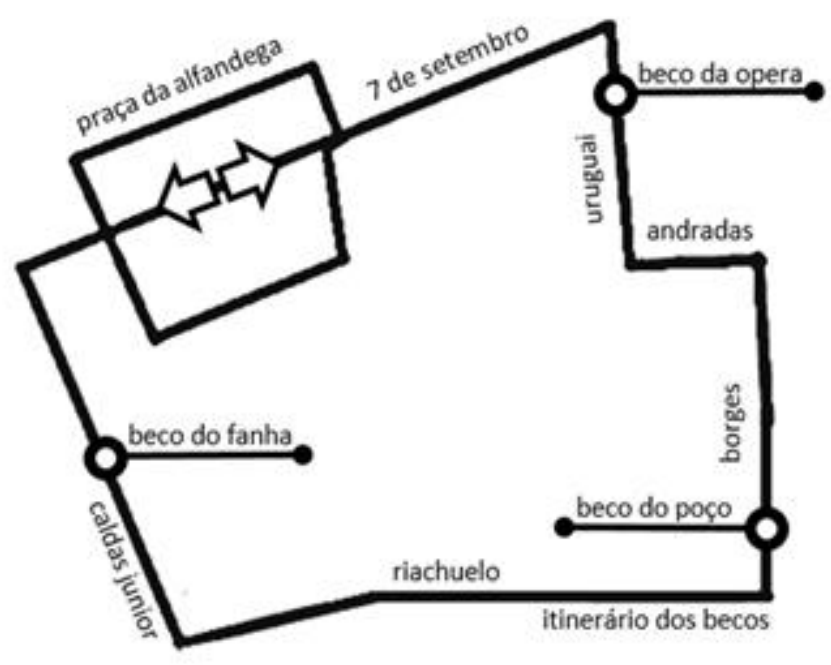

Fonte: criaçăo de Ulisses Filemon Leite Caetano (2016)

\section{Imagem 1 - Itinerário dos becos (peça gráfica número 1)}

O roteiro proposto inicia na Praça da Alfândega - sendo esse tanto o ponto de partida quanto o de chegada - e faz o seguinte trajeto, seguindo o mapa: 1. rua Sete de Setembro até rua Uruguai; 2. rua Uruguai (antigo beco da Ópera, no trecho entre a rua Sete de Setembro e a rua dos Andradas) até rua dos Andradas; 3. rua dos Andradas até a esquina com a avenida Borges de Medeiros; 4. avenida Borges de Medeiros (passando pelo antigo beco do Poço, situado onde hoje é o trecho entre a rua Andrade Neves e a rua Riachuelo) ${ }^{10} ; 5$. rua Riachuelo, seguindo até a rua Caldas Junior; 6. rua Caldas Junior (antigo beco do Fanha, no trecho entre a Riachuelo até a rua Sete de Setembro); 7. rua Sete de Setembro até a Praça da Alfândega.

\footnotetext{
10 * $\mathrm{O}$ antigo beco do Poço situava-se onde hoje é a avenida Borges de Medeiros, aproximadamente no trecho entre a rua Andrade Neves até a rua Duque de Caxias. Optou-se, nesse roteiro, por não seguir da rua Riachuelo até a rua Duque de Caxias. A escolha se deu em função de que nesse trajeto há o viaduto Otávio Rocha, (construído posterior à destruição do beco do Poço) e que está sob a rua Duque de Caxias, modificando o trajeto original do antigo beco. Outra justificativa se dá em termos de logística: ao invés de seguir reto na avenida Borges de Medeiros, em direção às ruas Jerônimo Coelho e Duque de Caxias, dobra-se à direita, na rua Riachuelo, seguindo até a rua Caldas Junior (beco do Fanha), mantendo o itinerário em forma de circuito.
} 
Os painéis ${ }^{11}, 2^{\text {a }}$ peça gráfica construída para o itinerário (Imagem 2), evidenciam as figuras representativas de cada beco, destacando as suas especificidades.
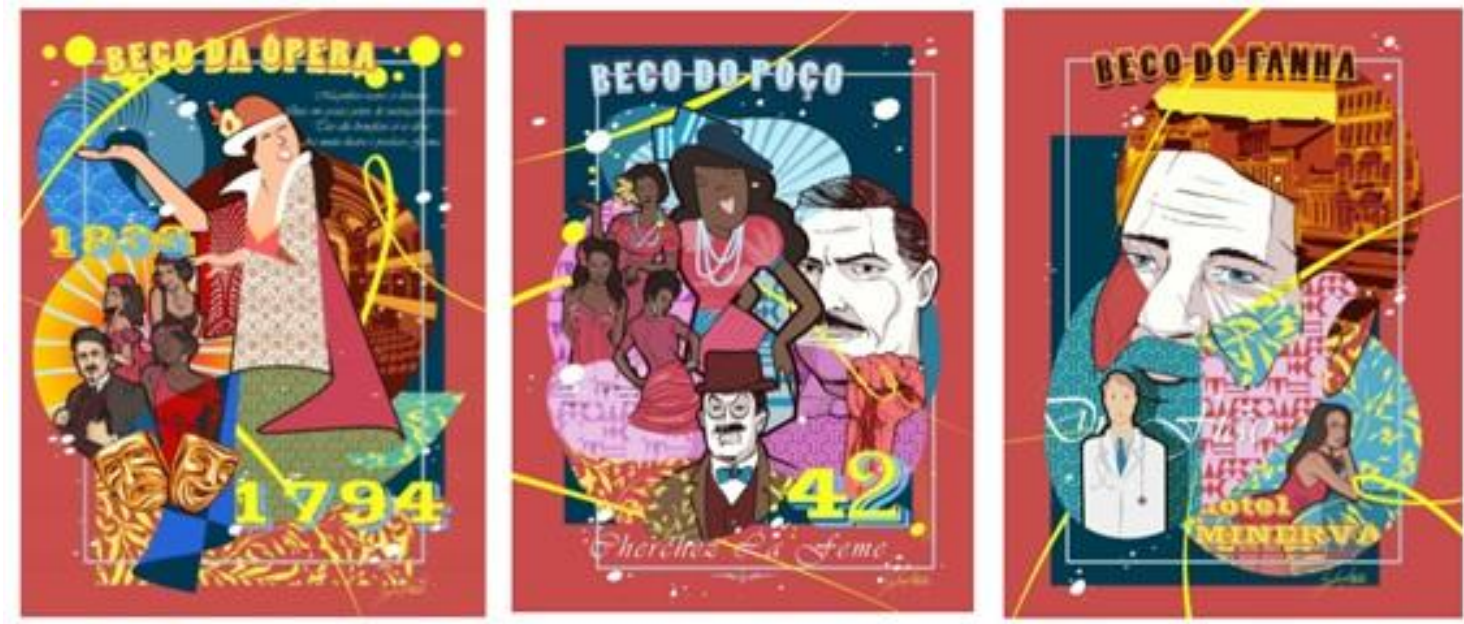

\section{Imagem 2 - Peça gráfica número 2: cartazes ilustrativos dos becos. Ilustrações de Stefen von den Heyder.}

O beco da Ópera está representado na ilustração gráfica, considerando os alguns elementos representativos, todos vinculados à Casa da Ópera. $\mathrm{Na}$ imagem representativa de um teatro, as características físicas da antiga Casa da Ópera, relatadas pelos cronistas porto-alegrenses, denotando um espaço precário, a partir da descrição de um comprido armazém ou de um barracão de madeira. A casa foi um marco, uma referência, tendo em vista que foi o primeiro teatro construído na cidade. Por isso a imagem de um espaço grande, belo e vistoso, vinculando aos imaginários da época.Duas datas importantes foram marcadas na ilustração: o ano de 1794, como aquele da construção da casa, e o de 1833, como o ano em que uma forte enchente atingiu a sua construção, vindo a ser destruída logo depois. As marcas d'água, em azul, representam a chuva e a enchente. No centro do painel, uma das personagens principais da Casa da Ópera, a atriz dona Benedita de Queirós Montenegro ou Dona Maria da Casa de Comédia, como assim a chamavam naquela época. Ao lado dela estão os demais personagens, representando os atores e atrizes que compunham as

\footnotetext{
${ }^{11}$ As ilustrações foram feitas pelo designer gráfico Stefan von den Heyder, entre outras, a partir de duas principais referências: as imagens características dos anos 1900, de ilustradores editoriais como J. Carlos e Calixtos e dos desenhos contemporâneos de arte urbana, remetendo às transformações ocorridas na Europa, principalmente na França, com o surgimento de movimentos como Art Nouveau e Art Deco.
} 
peças teatrais. À direita do painel, a frase colocada em frente ao palco do antigo teatro (da casa), homenageando o administrador benemérito da Casa da Ópera, Paulo José da Silva Gama.

Os elementos ilustrativos trazidos para o painel do beco do Poço possibilitam representar o cenário e os personagens de grande parte dos antigos becos da cidade de Porto Alegre, considerando, principalmente, o final do século XIX. Ali estão demarcadas parte das representações sociais da época, assim como os seus imaginários. A figura da famosa crioula Fausta, no centro da ilustração, representa a prostituição. O bordel, situado no beco do Poço (em uma casa de número 42), referese à conhecida espelunca "A Flor da Mocidade". E à sua esquerda está a presença de outras mulheres que, de uma forma ou de outra, contribuíram para a má fama do lugar. A expressão "Cherchez la Femme" ou "Procurea mulher" corrobora a essa questão, quando significava dizer que, em todo lugar que houvesse alguma briga ou desentendimento, havia uma mulher envolvida.

As duas figuras masculinas desenhadas na ilustração representam tanto os indivíduos que circulavam pelos bordeis e prostíbulos (marinheiros, homens casados, soldados, cáftens e entre outros), quanto aqueles que fortaleciam a estigmatização do beco como um espaço mal frequentado, sujo e perigoso. Também a população, através das crônicas dos jornais da época, notícias dos crimes, desordens, brigas e tudo que pudesse servir como alvo de discussões e polêmicas sobre o beco.

No centro do painel do beco do Fanha está representado o rosto do seu personagem principal, o Fanha. Além deste e com diferente estilo artístico está o Dr. Fião, personagem notório do lugar, além da figura do antigo "Hotel Minerva", com a prostituta debruçada sobre a bancada do bar. Nesse beco, assim como no beco do Poço, também havia estabelecimentos que instigavam o vício e os crimes, tais como casas de jogos, bordeis, bodegas, tavernas e prostíbulos. Na parte direita da ilustração, o desenho das edificações evidencia a construção das primeiras casas (desaparecidas com a destruição do beco), mas também os importantes edifícios erguidos anos mais tarde, os quais permanecem até hoje em sua materialidade, na atual Caldas Junior.

Além dos painéis, também foram criados outros materiais gráficos: um marcapágina, com glossário das personagens e lugares estigmatizados dos antigos becos, 
três cartões-postais, cada um representando um beco, contando a sua história e as suas particularidades e pôsteres (estilo "lambe-lambe"), com frases e textos que marcam a história dos becos.

$\mathrm{Na}$ imagem 3, veem-se imagens da realização do itinerário dos becos ${ }^{12}$, dinâmica que se aproxima de uma intervenção urbana, como uma das formas de aproximação entre o indivíduo e o espaço urbano, auxiliando também na compreensão da temática do itinerário histórico-cultural.

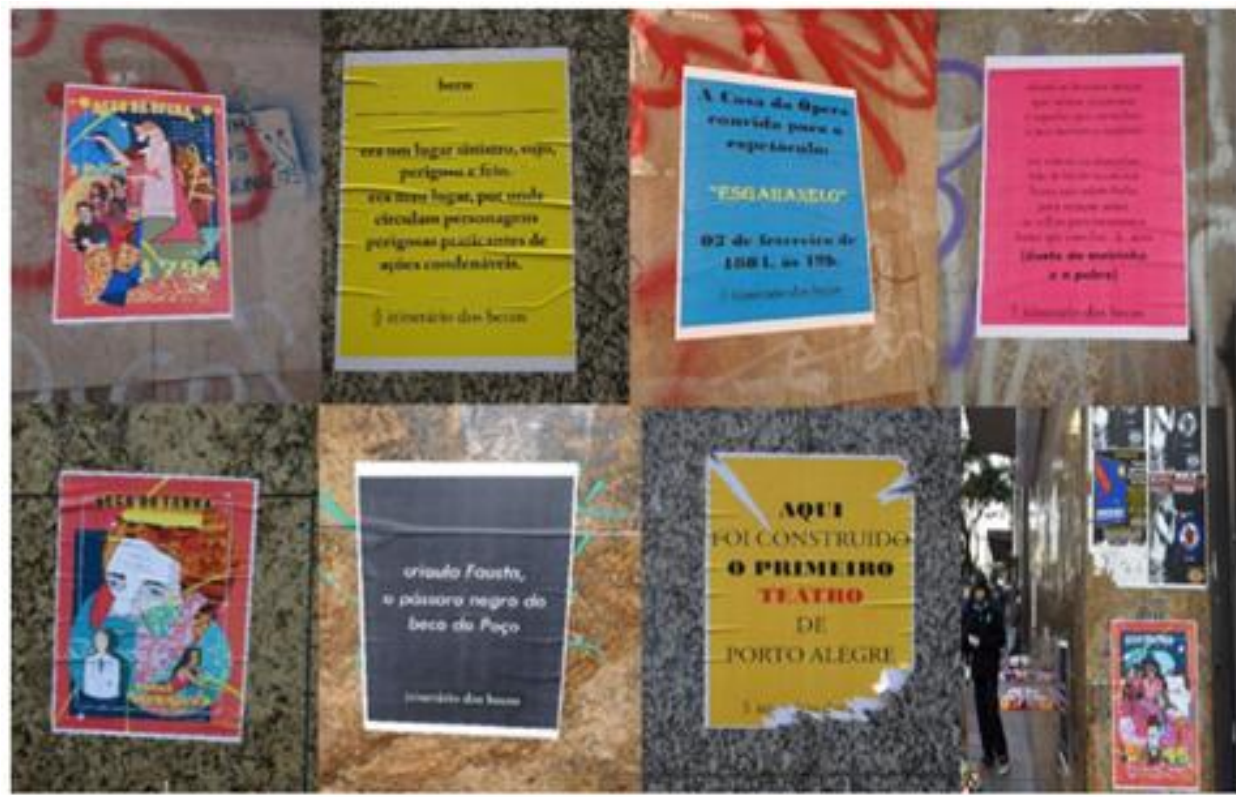

Imagem 3 - Imagens dos cartazes colados nas ruas de Porto Alegre, nos locais onde passou o itinerário em 25 de junho de 2016. Créditos das fotos das autoras. Fonte: Acervos pessoais das autoras (2016).

\footnotetext{
${ }^{12}$ O itinerário dos becos foi realizado dois dias após a banca de mestrado e contou com a presença da candidata, Luciana Gransotto, da orientadora, Nádia Maria Weber Santos, e de outros dez participantes convidados aleatoriamente. A atividade foi desenvolvida conforme a indicação do roteiro proposto, iniciando às $10 \mathrm{~h} 30$ do dia 25 de junho de 2016 e finalizando às $11 \mathrm{~h} 15$ desse mesmo dia. Foi profícuo observar o interesse das pessoas pelo desenvolvimento do itinerário, pela memória dos espaços e sua história. Ao final, observou-se, a partir dos comentários dos participantes, um enriquecimento de seu imaginário sobre a cidade e a curiosidade de permanecer estudando o espaço urbano ressignificado.
} 


\section{Considerações Finais}

O viés proposto nesse artigo foi levado a cabo a partir do entrecruzamento das noções de sensibilidades, imaginário urbano e suas sociabilidades presentes nas memórias dos locais (becos do final do século XIX e início do século XX da cidade de Porto Alegre),considerando todos estes elementos como constituintes fundamentais para a elaboração de um itinerário histórico-cultural. O pensamento de Pesavento (2004) contribuiu, ao enfatizar que é através das sensibilidades que "[...] os indivíduos e os grupos se dão a perceber, a si e ao mundo" (PESAVENTO, 2004, p. 222).

Os becos têm representatividade na origem e na transformação da cidade de Porto Alegre. Os becos do Poço, da Ópera e do Fanha têm importância na medida em que representam um território específico da urbs, com suas histórias, seus personagens e sua forma de ocupação, contribuindo para o entendimento da evolução e desenvolvimento de Porto Alegre.

Embora uma determinada experiência turística seja realizada em um mesmo tempo e espaço e cada indivíduo receba as mesmas informações que o grupo, a forma de assimilação será sempre diferente, ou seja, apreendida subjetivamente. Neste momento, a experiência individual se mescla com a experiência coletiva estabelecendo relação com a memória do lugar. Partiu-se da premissa de que toda experiência de memória é, ao mesmo tempo, individual e coletiva (SANTOS, 2013). E isto foi constatado pelo resultado da pesquisa realizada, no itinerário posposto.

Assim, os becos - inexistentes na realidade concreta da cidade - tornaram-se rememorações coletivas ao serem trabalhados a partir de imagens, textos e discursos sobre sua "passeidade" (PESAVENTO, 2001 a; b) e transformados em uma atividade turístico-cultural, ou seja, um itinerário.A cidade, vista com um palimpsesto de imagens e sentidos, é trazida aos olhares contemporâneos como fragmentos de significados que se interpõem e se mesclam, os quais são, ainda, ressignificados constantemente pela experiência sensível de cidadãos e viajantes.

Corrobora nosso pensamento a ideia de Leenhardt (2015), para quem a cidade é um "texto de textos", "a conjugação de vários textos imbricados uns nos outros, que devem ser lidos como um palimpsesto", e que "carregam [os textos] a marca do tempo 
e restituem, hoje, aos nossos olhos, a dissociação cada vez maior entre a arquitetura dos prédios da cidade e a cidade mesma como tecidos ou como gramática"(LEENHARDT, 2015, p.17).

Em relação ao espaço urbano, foi este o pensamento que norteou tanto a pesquisa como a escrita deste texto, como resultado e reflexão.

O que se observou no itinerário, de forma prática e direta, em relação aos locais e às receptividades das pessoas envolvidas, foi a recuperação de uma memória sensível dos espaços da antiga urbe, revalidados pela subjetividade e sensibilidade de cada um e de todos como um grupo que caminhava junto pelas ruas dos antigos becos transformados. Dessa forma, a memória, com seu aspecto de recriação e a sensibilidade que reconfigura a experiência, andam juntas. "A sensibilidade consegue, pela evocação ou pelo rememorar de uma sensação, produzir a experiência do vivido, reconfigurado pela presença do sentimento" (PESAVENTO, 2007a, p.13).

A memória imaginativa e sensível, componente intrínseco do exercício proposto durante o itinerário histórico-cultural,possibilitou novas formas de apreensão a impressões anteriormente concebidas (SANTOS, 2013). Teoricamente, é exatamente no momento da transmissão das imagens da memória que acontece algo: a transformação (recriação) das lembranças de conteúdos pessoais, nostálgicos em motivos coletivos, tornando a memória cultural e social. Assim, não se deve dissociar ambos aspectos da memória: individual/subjetivo (emoção/afeto) e coletivo/social e cultural (transmissão por imagens).

A posposta de pensar os becos do passado histórico longínquo da cidade, trazendo à tona memórias sobre eles, a partir de um exercício contemporâneo do turismo cultural, enriqueceu os campos dos saberes envolvidos e possibilitou a criação de uma nova categoria de interpretação, os itinerários histórico-culturais, como foi mencionado no início deste trabalho, agregando novas reflexões e sentidos para a questão do espaço urbano e suas inter-relações. 


\section{Referências}

ASSMANN, Aleida. Espaços da Recordação - formas e transformações da Memória Cultural. Campinas: editora da UNICAMP, 2011.

BARROS, José d'Assunção. Igualdade, desigualdade e diferença: contribuições para uma abordagem semiótica das três noções. In:

Revista de Ciências Humanas, Florianópolis, EdUFSC, n 39, 2006, pp. 199-218.

CERTEAU, Michel de. A invenção do cotidiano. Tradução de Ephraim Ferreira Alves. Petrópolis: Vozes, 2007.

FEBVRE, Lucien. La sensibilité et I' histoire - comment reconstituer la vie affective d'autrefois? In: Chartier, Roger. et al. La sensibilité dans I' histoire. Paris: Gérard de Monford, 1987.

GRANSOTTO, Larissa. Cabo Polônio: uma viagem através das utopias urbanas. (Mestrado em Arquitetura) Porto Alegre: UFRGS, 2009.

GRANSOTTO, Luciana. Itinerário histórico-cultural dos becos de Porto Alegre no final do século XIX. (Mestrado em Memória Social e Bens Culturais) Canoas: UNILASALLE, 2016.

LEENHARDT, Jacques. A teoria do 'beco': história geral e história cultural da cidade na obra de Sandra Jatahy Pesavento. In: LEENHARDT, Jacques, SANTOS, N.M.W. et al. História cultural da cidade - Homenagem à Sandra Jatahy Pesavento. Porto Alegre: MARCA VISUAL/PROPUR, 2015.

MELLO, Bruno. A cidade de Porto Alegre entre 1820 e 1890. As transformações físicas da capital a partir das impressões dos viajantes estrangeiros. (Mestrado em Arquitetura) Porto Alegre: UFRGS, 2010.

MICHEL, Frank. Désirs d'Ailleurs: essai d'Antropologie des Voyages. Quebec: Les Presses de l'Université Laval, 2004.

PÉREZ, Xerardo. Turismo cultural. Uma visão antropológica. Tenerife, Espanha: Asociación Canaria de Antropología, 2009. 
PESAVENTO, Sandra Jatahy. Uma outra cidade: o mundo dos excluídos no final do século XIX. São Paulo: Companhia Editora Nacional, 2001a.

PESAVENTO, Sandra Jatahy. Era uma vez o beco: origens de um mau lugar. In: BRESCIANI, Maria Stella (Org.) Palavras da cidade. Porto Alegre: Ed. Universidade/UFRGS, 2001b. p. 97-119.

PESAVENTO, Sandra Jatahy. Crime, violência e sociabilidades urbanas: as fronteiras da ordem e da desordem no sul brasileiro no final do séc. XIX. In: Estudos Ibero-Americanos, Porto Alegre, v. 30, n. 2, p. 27-37, dez. 2004.

PESAVENTO, Sandra Jatahy. Sensibilidades no tempo, tempo das sensibilidades. Nuevo Mundo Mundos Nuevos [En ligne], Colloques, mis en ligne le 04 février 2005a, consulté le 02 avril 2017. Disponível em: http://nuevomundo.revues.org/229 PESAVENTO, Sandra Jatahy. Cidade, espaço e tempo: reflexões sobre a memória e o patrimônio urbano. In: Cadernos do LEPAARQ, V. II, n4. Pelotas, RS: Editora da UFPEL. Ago/Dez 2005b. Disponível em: $<$ https://periodicos.ufpel.edu.br/ojs2/index.php/lepaarq/article/viewFile /893/873> Acessado em 02/04/2017.

PESAVENTO, Sandra Jatahy. Sensibilidades: escrita e leitura da alma. In: PESAVENTO, Sandra, LANGUE, Frédérique. (orgs). Sensibilidades na História: Memórias singulares e Identidades urbanas. Porto Alegre: Ed. da UFRGS, 2007a.

PESAVENTO, Sandra Jatahy. Cidades visíveis, cidades sensíveis, cidades imaginárias. Revista Brasileira de História, São Paulo, v. 27, n, 53, jan./jun. 2007b.

PESAVENTO, Sandra Jatahy. História \& História Cultural. 3. ed. Belo Horizonte: Autêntica, 2012.

PESAVENTO, Sandra Jatahy. Beco (verbete). In: TOPALOV, C; BRESCIANI, S; DE LULLE, L. C; RIVIÈRE D'ARC, H. A aventura das palavras da cidade através dos tempos, das línguas e das sociedades. São Paulo: Romano Guerra, 2014. 
RICOEUR, Paul. L'écriture de l'histoire et la représentation du passe. In: Annales. 55 année, (4), juillet/aôut 2000, p. 731-749.

SANTOS, N. M. W.. Memória como narrativas do sensível: entre subjetividades e sensibilidades. In: Cleusa Maria Gomes Graebin Nádia Maria Weber Santos. (Org.). Memória Social: questões teóricas e metodológicas. Canoas: UniLasalle, 2013, v. 1, p. 131-156. SANTOS, N. M. W. GRANSOTTO, L. Expérience touristique dans des circuits patrimoniaux: une approche interculturelle Brésil-Canada. In: Zilá Bernd Patrick Imbert. (Org.). Envisager les rencontres BrésilCanada. Quebec: Presses de I'Université Laval, 2015, v. 1, p. 213-235.

SANTOS, N. M. W. GRANSOTTO, L . Imaginário Turístico e o território sensível do outro: uma observação sobre o Centro Histórico de Porto Alegre. In: Cléria Botelho Maria do Espírito Santo Rosa Cavalcante Ribeiro. (Org.). Fronteiras móveis: territorialidades, migrações. 1ed.Belo Horizonte: Fino Traço, 2016, v. 1, p. 267-282. 